\title{
Hemophilic Arthropathy
}

\author{
Babajide O Olubaniyi, Olubukola Ajala, David C Howlett
}

\section{CASE REPORT}

A 34-year-old male with hemophilia A presented to the emergency department with pain and swelling in his left knee following a minor fall. He was known to suffer from advanced arthropathy and was awaiting a total knee replacement. On clinical examination, the left knee was swollen and tender with a reduced range of movement. Plain radiograph (antero-posterior and lateral views) performed (Figures 1 and 2) excluded a fracture or dislocation but demonstrated classic appearances of hemophilic arthropathy with severe secondary degenerative changes. He was discharged with adequate simple analgesia and outpatient follow-up appointments with his hematologist and physiotherapist.

\section{DISCUSSION}

Hemophilia is an inherited, $\mathrm{X}$-linked recessive disorder caused by deficiency of plasma clotting factors VIII, IX or XI. It manifests in males while females are asymptomatic carriers. Hemophilic arthropathy

Babajide O Olubaniyi ${ }^{1}$, Olubukola Ajala ${ }^{2}$, David C Howlett $^{3}$ Affiliations: ${ }^{1} \mathrm{FRCR}$, Department of Radiology, Eastbourne District General Hospital, King's Drive, Eastbourne, East Sussex, BN21 2UD, United Kingdom; ${ }^{2} \mathrm{MRCP}$, Department of Diabetes and Endocrinology, Western Sussex NHS Trust, Worthing Hospital, Lyndhurst road, BN11 2DH, United Kingdom, ${ }^{3} \mathrm{FRCR}$, Department of Radiology, Eastbourne District General Hospital, King's Drive, Eastbourne, East Sussex, BN21 2UD, United Kingdom.

Corresponding Author: Dr. Babajide O Olubaniyi, Department of Radiology, Eastbourne District General Hospital, King's Drive, Eastbourne, East Sussex, BN21 2UD, United Kingdom; Tel: +441323417400, Extension 4673; Email: jide. olubaniyi@nhs.net

Received: 03 June 2013

Accepted: 30 July 2013

Published: 01 December 2013

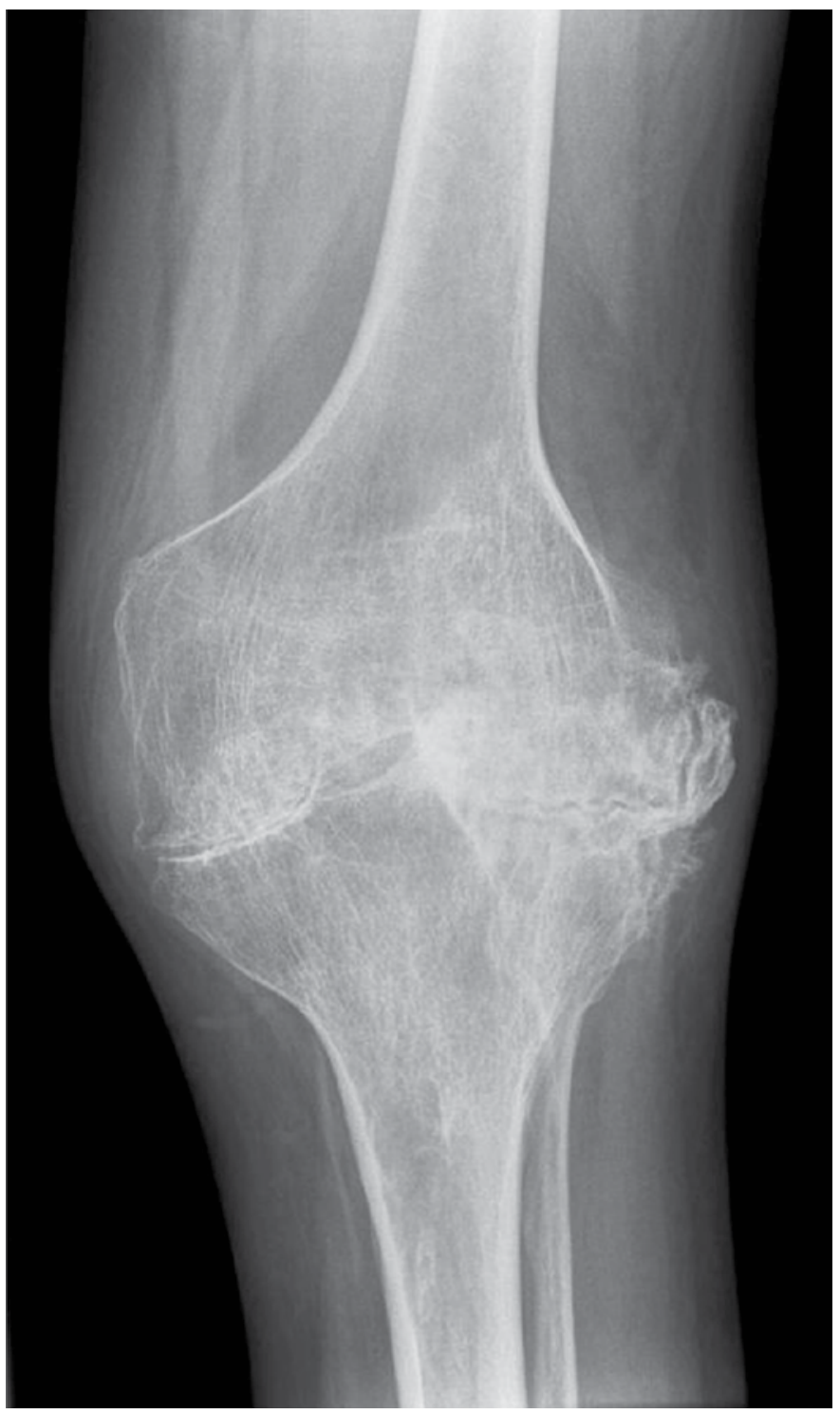

Figure 1: Anteroposterior radiograph of the knee showing widened intercondylar notch, bulbous femoral condyles, flattened condylar surfaces, periarticular osteoporosis, marked loss of articular cartilage, sclerosis, and osseous proliferation. 


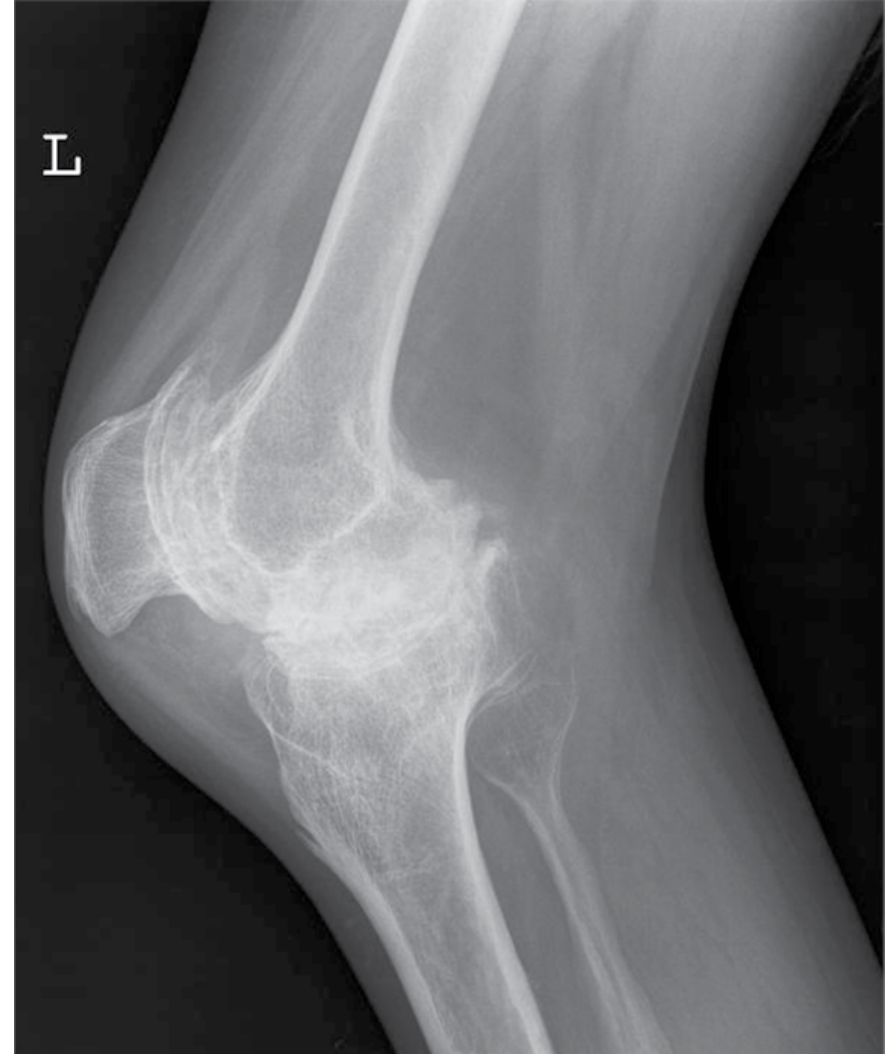

Figure 2: Lateral radiograph of the knee showing squared inferior margin of the patella and severe degenerative changes in the patellofemoral and tibiofemoral compartments.

results from repeated episodes of hemarthrosis, blood within the joint damages the articular cartilage directly [1]. Large joints (knee, ankle, elbow, and shoulder) are usually affected. The classic appearance of hemophilic arthropathy in the knee is shown in Figures 1 and 2, i.e., widened intercondylar notch, bulbous femoral condyles, flattened condylar surfaces and squared inferior margin of the patella [2]. Due to repeated episodes of hemarthrosis, our patient also had severe secondary osteoarthritic changes with near-total joint space loss. Hemophilic arthropathy most often begins in the first or second decade of life and bleeding episodes tend to recur in the same joint with gradual progression to joint destruction. Recurrent hemarthrosis inevitably leads to synovial hyperplasia, subchondral resorption, erosions, articular cartilage destruction, joint space narrowing, and osseous proliferation. Periarticular osteoporosis and epiphyseal overgrowth occurs due to associated joint hyperemia. Clinical presentation varies according to disease severity with pain and joint swelling during acute episodes of hemarthrosis and progressive loss of joint function in longstanding cases. Prophylactic replacement of deficient clotting factors in the first or second decade of life may prevent or delay joint destruction in children with severe hemophilia [3]. Patients who present with an acute bleeding episode require adequate pain relief, prompt administration of deficient clotting factor and rest. Patients who suffer from repeated hemarthrosis despite optimal conservative management may benefit from synovectomy. Patients with end stage disease may require surgical arthrodesis or total joint replacement to control pain and restore some function as planned for our patient.

\section{CONCLUSION}

Hemophilia can cause progressive joint destruction and loss of function. Early prophylactic treatment in children with severe hemophilia can prevent or delay joint destruction.

\section{$* * * * * * * * *$}

Olubaniyi BO, Ajala O, Howlett DC. Hemophilic Arthropathy. International Journal of Case Reports and Images 2013;4(12):745-747.

$* * * * * * * * *$

doi:10.5348/ijcri-2013-12-426-CL-20

\section{Author Contributions}

Babajide O Olubaniyi - Substantial contributions to conception and design, Acquisition of data, Analysis and interpretation of data, Drafting the article, Revising it critically for important intellectual content, Final approval of the version to be published

Olubukola Ajala - Acquisition of data, Drafting the article, Revising it critically for important intellectual content, Final approval of the version to be published David C Howlett - Substantial contributions to conception and design, Acquisition of data, Revising it critically for important intellectual content, Final approval of the version to be published

\section{Guarantor}

The corresponding author is the guarantor of submission.

\section{Conflict of Interest}

Authors declare no conflict of interest.

\section{Copyright}

(C) BO Olubaniyi et al. 2013; This article is distributed under the terms of Creative Commons attribution 3.0 License which permits unrestricted use, distribution and reproduction in any means provided the original authors and original publisher are properly credited. (Please see www.ijcasereportsandimages.com/copyright-policy.php for more information.) 


\section{REFERENCES}

1. Jansen NW, Roosendaal G, Bijlsma JW, DeGroot J, Lafeber FB. Exposure of human cartilage tissue to low concentrations of blood for a short period of time leads to prolonged cartilage damage: An in vitro study. Arthritis Rheum 2007 Jan;56(1):199-207.
2. Llauger J, Palmer J, Rosón N, Bagué S, Camins A, Cremades R. Nonseptic monoarthritis: Imaging features with clinical and histopathologic correlation. Radiographics 2000 Oct;20 Spec No:S263-78.

3. Manco-Johnson MJ, Abshire TC, Shapiro AD, et al. Prophylaxis versus episodic treatment to prevent joint disease in boys with severe haemophilia. $\mathrm{N} \mathrm{Engl}$ J Med 2007 Aug 9;357(6):535-44.
Access full text article on other devices

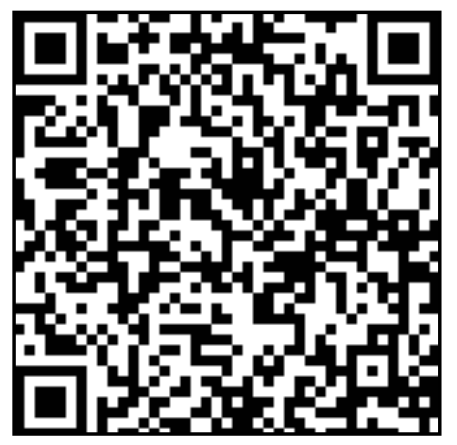

Access PDF of article on other devices

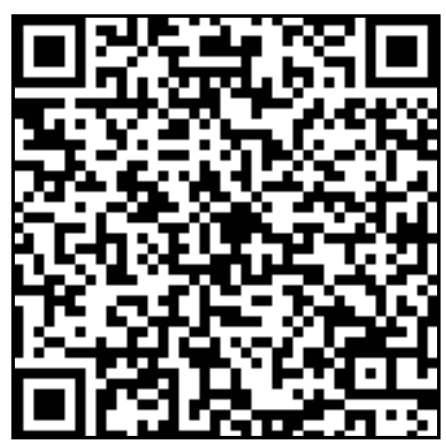

